\title{
THE NECESSITY OF CHANGES IN THE HIGHER EDUCATION IN BULGARIA
}

\author{
Venelin Terziev ${ }^{1}$, Marusya Lyubcheva ${ }^{2}$, Katia Mihailova ${ }^{3}$ \\ ${ }^{1}$ Full Member of the Russian Academy of Natural History, Professor, Eng., D.Sc. (National \\ Security), D.Sc. (Economics), D.Sc. (Social Activities), Ph.D. Russian Academy of Natural History, \\ Moscow, Russia; Georgi Rakovski Military Academy, Sofia, Bulgaria; University of Rousse, \\ Rousse, Bulgaria; Kaneff University Hospital, Rousse, Bulgaria, vkterziev@gmail.com \\ ${ }^{2}$ Associate Professor, Ph.D., University „Prof. d-r Assen Zlatarov”, Bourgas, Bulgaria, \\ milyubcheff@gmail.com \\ ${ }^{3}$ Associate Professor, Ph.D., University of National and World Economy (UNWE), Sofia, Bulgaria, \\ katiamihail@gmail.com
}

\begin{abstract}
This work is an attempt for a brief analysis of the new "Strategy for the development of higher education in the Republic of Bulgaria for $2021-2030$ " and is searching for an answer to the new challenges facing the education system. Searching and finding the right solutions in this direction does not only require specific skills and competencies, but also sufficient experience, information and knowledge in this direction. This challenge cannot and should not be the action of just one person, but of a group of scientists, researchers and politicians with a sufficiently high level of expertise that would contribute to the development of an objective and accurate action plan.
\end{abstract}

Keywords: economy, changes, higher education, adequate reforms.

\section{INTRODUCTION}

It is often said that higher education itself is directly related to the economy and has a significant impact on labour market, causing changes in the ratio between the various categories of professionals seeking their realization in the primary labour market.

In fact, the influence of higher education as a system is formed in a certain framework format. The influence of knowledge, skills and competencies that higher education offers and implements through human capital is informal, but significant. It is human capital that influences technologies, processes, systems ... In order for this influence to correspond to the priorities of development of our society in the conditions of Industry 4.0, the education that creates human capital must differ from that which shaped the qualities of the workforce ten or more years ago.

\section{THE NEED OF CHANGES IN BULGARIA'S HIGHER EDUCATION}

Higher education has always sought changes that would make it adequate to the current requirements. The question is who formulates them, what these requirements are and whether those who determine the requirements are aware of what needs to happen. Generally, these are representatives of the economy /those who manage economic processes, representatives of different types of business, representatives of 
financial capital, etc./. Certainly such requirements will be practical focused to solve specific and often shortterm tasks and problems. Therefore, other participants should be engaged, and in practice they are the representatives of the higher education system itself. It is the intellectual elite who is expected to know the system well from the inside, but also to know the processes of the society's development, who can anticipate and manage this development. Only in this case the requirements towards the higher education will not be unilateral and short-term, and will not serve only certain business interests, which is often the case when discussing changes in higher education, but will guide changes in public development.

In this sense, the real question is what changes are needed in higher education in order for the human capital that it forms to solve the challenging and complex tasks of technology development /with the understanding that everything in the field of economics is technology/. Today we are talking about the modernization of higher education - because it has to correspond to computer and communication technologies, to digital processes, to high technologies in materials science. And this means determining what to study, the appropriate periods for it, the relevant methods and to what extent modern scientific achievements will enter the education process, so that it is not only based on the conventional foundations that distance it from modern solutions.

One step towards changes in education in general is the National Qualifications Framework, created on the basis of the recommended European Qualifications Framework.

The next steps towards changes are determined by the changing role of higher education - from the one adapting to change, to the one leading it and offering integrated knowledge that corresponds to the integrated development of the society:

- The appropriate orientation of higher education /we can call it diversification of higher education different trainings in terms of type and duration, which provide a certificate of higher education/;

- Clear, accurate and uniform criteria for creating a ranking of higher education institutions;

- Monitoring and assessment of compliance with academic standards in higher education institutions;

- Investments in higher education, which are vital for overcoming the established stagnation in the system in the last ten years or more;

- Improving teaching and research in all areas of higher education by involving students and providing additional key qualifications that meet the dynamic requirements of the labour market;

- Providing the necessary information for defining and respectively for developing curricula, covering both general knowledge and specific professional skills through lifelong learning, in constant dialogue not only with those involved in the field of teaching, but also with society as a whole and the state;

- Introducing entrepreneurship as an element of mandatory creative preparation of students to ensure mobility and a higher perspective for subsequent realization;

- Developing a system for forecasts and development of social and economic processes in order to provide training in new professional fields and professions.

The changes will lead to the creation of a new generation of human capital /so called type of experts/ who will be able to change the scale of economic development - acceleration, efficiency, effectiveness, flexibility, competitiveness, security, safety, i.e. human capital will work for intelligence growth.

Changes in higher education will lead to improved quality of teaching, the introduction of research in the teaching system and an improved set of knowledge, skills and competencies with which professionals will be able to compete in the labour market. This can lead to saturation of the labour market with specialists with higher education, but if we follow the model of key competencies, the realization of specialists will be normal. This would be helped by the good structure of higher education, which offers different qualifications, thus responding to the prevailing trend of "over qualification" for certain job positions.

Need of higher awareness, which is related to:

- Collection and publication of statistics on the correspondence between different levels of higher education and employment opportunities;

- Creation of information databases for professional orientation, employment and labour force dynamics in the regional and national labour market;

- Achievement of good dependence on the labour market with the help of Lifelong Learning Programme 
and additional motivating programmes to ensure the mobility of young professionals, and with these changes the market will become more competitive, but at the same time more mobile and dynamic.

The draft Strategy for Development of Higher Education in the Republic of Bulgaria for the period 2021-2030 was developed by the Ministry of Science and Education. The draft is influenced by the Strategy for Development of Higher Education in the Republic of Bulgaria for the period 2014-2020. The draft is aimed at improving the quality of Bulgarian higher education. It proposes an extremely concise „vision" for the development of higher education - in just two sentences. Its aim is „a differentiated and flexible system of higher education institutions - partners and competitors to European ones, carrying out educational, research and cultural mission for the benefit of society and individuals through research and quality education and to build an academic community" (2020).

10 priority areas for development, 10 goals, 27 activities and 142 measures are planned for the purposes of the draft. All of them are in the spectrum from revision of curricula and programmes, updating teaching approaches and methods through management and accreditation of universities, connection between education - science - business, to reformatting the system of higher education institutions in the country.

In terms of content, the draft sets 4 fundamental proposals for the development of higher education by 2030 . Each of them individually and all of them together have a real potential to fundamentally transform the system of higher education in our country. The question is whether this transformation will lead to an increase in the quality of the education offered by universities and colleges, as is the declared goal of the Strategy or the opposite?

Each of the proposals requires serious expert consideration, and this cannot happen without discussion within the current university and academic community, as well as in the society in general.

It is clear that the proposals are made first in the strategic documents, and after the strategies are adopted the new proposals are reasonably included in the legal regulation of the respective social system.

\section{About the fundamental proposals for the development of higher education}

One of the proposals is to change the duration of studies for the academic degree „Bachelor" to 3 years. The question is whether this will not lead to role conflict among students and lecturers.

„Legally introduced opportunity for full-time study in the Bachelor's degree with a duration of 3 academic years" (2020).

The idea of three stages of higher education with a recommended duration for each degree respectively: academic degree „Bachelor" - 3 years, academic degree "Master" - 2 years and academic degree „Doctor" -3 years is set in the so-called Bologna Process of 1999.

The draft of the Strategy states that the implementation of the Bologna Process instruments in our country is „insufficiently effective and often formal“. The same is defined as „a major challenge related to the insufficient internationalization of Bulgarian higher education" (2020). "Accelerated internationalization and full integration into European education and research networks" is ranked among the 10 priority areas for higher education development. This is also the fourth goal of the Strategy. Therefore, according to the Ministry of Education and Science, reducing the duration of bachelor's degree and increasing the duration of master's degree by one year is a measure that is expected to improve the quality of education.

Many European and American universities already have a 3-year duration of study for the Bachelor's degree, a 2-year duration of study for the Master's degree and a 3-year duration for the Doctor's degree. This accumulated foreign experience shows the results and drawbacks of the system and should be taken into account when developing the Strategy, but this analysis and these elements are missing in the current proposal.

Currently, the Bachelor's degree programme in Bulgaria lasts 4 years and the Master's degree programme is from 1 to 2 years. The duration of programmes in the first two degrees is 5-6 years. According to the planned opportunity to reduce the Bachelor's degree by 1 year, and to make the Master's degree with a fixed duration of 2 years, the total duration will remain 5 years again. So, technically the proposal for a 3-year duration of study for a Bachelor's degree is not such a dramatic change.

Wouldn't such arithmetic turn out to be wrong if we consider the fact that some students do not continue their studies in a master's degree? For them, the studying process will be reduced from 4 to 3 years and this will lead to less time for acquiring and developing certain knowledge and to a lower level of skills.

In a sense, this contradicts the idea of lifelong learning, which is also part of the Strategy. Lifelong learning 
implies, on the one hand, a longer duration of university studies and, on the other hand, the attraction of nontraditional groups of students, following the example of Spain and other countries where adult universities are quite common.

The transition to a 3-year duration of study for a Bachelor's degree requires an increase in the semester workload of students to meet certain standards (accepted for this type of study). Each semester will be required to contain at least one or two more subjects to meet the minimum credits required to complete this degree. The number of credits does not decrease in proportion to the reduction in the duration of studying. This implies devoting most of the time to study. Given the fact that most students today are forced to combine study and work, and they actually do it, increasing the workload will reduce working time, i.e. income for their daily life and this will be compensated in a certain way.

The majority of working students are more likely to choose their work at the expense of their studies, as they do now. In this situation, it is pointless to believe that reducing the period of study for a Bachelor's degree will increase the quality of higher education.

Today's Bulgarian full-time students face the dilemma: studying or working. This is one of the serious problems that reduce the quality of the education received by the students, cause a negative attitude towards higher education and lead to inefficient spending of public state resources.

For each full-time student getting state-funded education, the state pays a subsidy so that they can complete their education. While they work, they miss their lectures and so the subsidy turns out to be pointless. The Strategy does not take a stand on this key issue and does not provide an answer.

This leads to another problem - for example, the dropout of students during the years of study. So far, most universities have managed to ensure the admission of a sufficient number of students, but retaining a large number of admitted students until the end of the educational programme proves difficult. This problem, as statistics show, is becoming increasingly difficult for the education system and cannot be ignored.

Another important issue, which is of purely social nature and which the Strategy for higher education should take into account or is that a large number of students choose this period to start a family and have children. These students, like in the case with working students, will be forced to miss most of their lectures so that they can take care of their family and children. The draft recognizes the demographic crisis as a challenge to the quality of higher education (2020), but it does not consider that the creation of additional conflict and difficult compatibility between family-parental and educational commitments of students is in contrast to the stated: "ensuring access to higher education and high-quality lifelong learning that supports personal development and professional realization "(2020).

On the other hand, a 4-year Bachelor's degree allows students to choose the length of their studies and take responsibility for their choices and consequences. Everyone has the right to complete 2 years of education in 1 , which usually happens in the 3rd and 4th year of the studying, provided that the grades from the previous year are very high. Students of a 3-year Bachelor degree have the right to extend their studies to 4 or more years by interrupting them. Restricting the opportunities for students to choose is in contradiction with the measure for the development of competencies for successful personal and professional realization within the digital environment (2020).

In the digital environment, which is a key element of the information society (A. Toffler) or in the network society (M. Castells), the ability to make quick and adequate decisions, make choices and take responsibility for choices is a cornerstone of personal and professional success of the modern young man. Giving the opportunity to choose develops cognitive and non-cognitive competencies, teaches the young person to balance the rational and emotional component in each of their decisions and actions. Achieving a balance in the development of cognitive and non-cognitive competencies is set as measure 1.1.2 in the Draft (2020).

The proposal for the three years, if it is the result of serious strategic thinking, should be substantiated with reliable research results and forecasts regarding the quality of higher education in our country to date. This analysis is currently lacking.

"Quality" is a key word in the Draft, but the presented "Analysis of the environment and the state of the higher education system" (2020) does not give sufficient grounds to think that the actually achieved level of quality requires a reduction of the duration of the first degree of higher education by 1 year. On the contrary a number of problems are listed that are related to the preparation and motivation of teaching staff, the relevance of curricula, flexibility and adequacy of teaching approaches and methods, teacher certification, management and accreditation and the structure of the university system. All of them, individually and collectively, negatively affect the quality and do not justify the reduction of the duration of the first degree of 
higher education by a whole year.

In the Quality Improvement Strategy, the financial aspect to reduce government spending and thus funding of a Bachelor's degree prevails. This action would give a short-term and one-way result.

The specific arguments defined in the Strategy are the criteria for assessing "high quality" and progress in higher education reform, which is presented in the "Summary of progress in meeting the main objectives of the Strategy 2014-2020." Emphasis is placed on additional funding, student loans, increased scholarships, benefits for students with disabilities, as well as funds/ benefits under various EU structural programs. Criteria for the content of educational material, for modern and attractive teaching, for quality research and experience, for acquired high professionalism are lacking. All this is the content of the generalizing "quality of higher education, which is omitted in the criteria for the period 2014-2020 and which gives rise to certain concerns for the next period 2021-2030.

\section{About another proposal related to Stimulation of young teachers.}

In this situation the logical question arises whether it won't stimulate intergenerational conflict among our academic community, the results of which would be unpredictable.

„Well-motivated young teachers united in flexible inter-university academic, cultural and sports programmes“ (2020).

Stimulating the development of young teachers is one of the good proposals set out in the draft. Young teachers are understood as non-habilitated lecturers - assistants and chief assistants. They are opposed to teachers over the age of 60 , who according to the Ministry of Education and Science represent $23 \%$ of the total teaching staff in Bulgaria. Therefore, young teachers and middle-aged teachers are about $77 \%$.

This is currently not a bad, but rather an optimal generational (age) structure of university lecturers.

The draft of Strategy includes realization of certain measures such as financial incentives by redefining the teaching remuneration - from oriented to work experience and length of service to the achieved quality of the educational process and research, commitment to the professional realization of students. It also proposes preferences for draft funding and even university funds to finance the participation of young lecturers in international research projects and forums (2020). It also suggests supporting the process of habilitation of young lecturers in "short terms while maintaining high academic standards" (2020).

These proposals would lead to a good career start and support in the development of young lecturers, which is undoubtedly a problem at the moment.

The first question is how do short deadlines combine with high academic standards in the process of habilitation?

The habilitation, in addition to writing and publishing a certain amount of scientific papers, also requires a level of experience in teaching, achieved teaching and pedagogical skills. This experience can neither be gathered nor realized and turned into working patterns of behaviour in a short time. It is difficult to achieve high quality research products in a short time.

Only the preparation of a dissertation research takes at least three years. Research that grows into authorial monographs according to high academic standards is also difficult to carry out in shorter time. In science you need time to study, do research, comprehend the relevant issues, if the goal is to achieve high quality.

The second question is related to the attitude of the Ministry of Education and Science towards middle-aged and senior lecturers - experienced lecturers and those who have undisputed authority.

The draft of Strategy for Development of Higher Education does not set goals, does not envisage actions and measures to stimulate lecturers of the second age category (if we can define it that way) - the active generation of 40-50 year olds, and the third age category - the so-called established lecturers. They are mentioned only in terms of measures aimed at increasing digital literacy. At the same time, the quality of higher education is directly dependent on the age balance, knowledge and experience achieved by different generations of lecturers.

Therefore, the Strategy should stimulate lecturers of all ages, because they all have their specific needs and competencies. A number of questions arise: Don't older lecturers need a „personal, high-tech workplace“, as envisaged for young people (2020), especially given the „universal digitalisation” project? How many teachers today have a personal workplace? How many lecturers today have been forced to urgently look for high-tech equipment to conduct their lectures and exams online? These are the problems that characterize 
the entire teaching staff and do not depend on their age characteristics.

Undoubtedly, young people need support to take their first steps in the teaching and research field, and to establish and develop their professional career at the university, but lecturers around and over 60 years old with their rich knowledge, experience, high expertise, human and professional wisdom - also need some support to make their steps to the next stage of their lives, where they will continue to feel complete, continue to work creatively, will be given the opportunity to use of their high competence and experience.

The third proposal is related to the digitalization of the educational process - online learning.

„Digital university environment, providing continuous intellectual stimulation and the possibility of distance elearning" (2020).

The developers of the Strategy repeatedly discuss the "digitalization" of the learning process, of the relevant learning resources and content, of the relevant educational approaches, methods and practices, of the administrative services and of the education system as a whole. The adjective "digital" in combination with technology, content, teaching, forms of training and testing, competencies, creativity, generation, environment, transformation, is also very often found in the programme document. This means that practically every second page of the Draft contains the topic of digitalization of the university educational process or, as it is precisely says, „universal digitalization“ (2020).

It is noteworthy that the term "online learning", which has long been accepted and defined in the scientific community and has already gained wide civic recognition, is not used once in the Draft. This logically raises the following questions:

- Do the Ministry of Education and Science and the higher education speak the same language?

- A negative answer could lead to serious problems in the education system and the quality of higher education, especially due to insignificant misunderstandings between the countries.

- Is the Ministry of Education and Science not trying to find a substitute verbal formula for online learning and proposing "universal digitalisation"?

- This kind of "synonymization“, in which „things are not called by their real names“ serves to cover up „some defect", as Dimitar Bezhanski says in the story of Grandpa Stanko, „who had a speech defect and could not pronounce "r" sound and so he had developed a whole system of speech in which he did not have to use the hated sound "r" (2020). If this is also the case, what "defect" does the Ministry of Education and Science cover up by systematically imposing "universal digitalisation" instead of "online learning"? Perhaps the direct proposal for the full introduction of online learning in universities and colleges will meet with serious resistance in academia and civic circles?

- Perhaps the Ministry of Education and Science is developing the Strategy for Development of Higher Education in Bulgaria on the basis of a literal translation of the relevant EU strategic documents, which are duly cited at the beginning of the Draft itself. Such a decision can be explained by Bulgaria's membership in the EU and specifically by the goal of integrating Bulgarian higher education in the European educational space. Even so, isn't it right for the strategic documents for the development of Bulgarian education to be thought and written in the context of the national cultural peculiarity, language and shared knowledge?

„Digitalisation has become a key tool for ensuring access to quality higher education“ (2020), the Draft of the Strategy states.

Such a statement is inaccurate, to say the least. Through digitalisation, people can more quickly and easily find information about the educational services offered by universities. However, their access to higher education, does not depend on digitalisation, but mostly on whether and how they pass their admission exams. The exams can be online or offline - digitized, via the Internet or in its traditional form. In both cases of admission exams they lead to the same quality of educational services offered at the university. To say that digitalization provides access to quality higher education in this logic means that online exams lead to quality education, and traditional admission exams - to lower quality.

Digitization is a "material process of converting analogue information streams into digital streams" as correctly defined in the Draft (2020).

In terms of learning content, this means that current analogue learning content on paper, mainly in text form, is converted to digital, i.e. electronic and accessible via Internet connection. The quality of the electronic educational content on the Internet should be the same as the quality of the traditional educational content on paper. 
There is a certain illusion that electronic learning content is more accessible than traditional paper content in a book. The illusion is supported by a series of other illusions such as:

- Everything can be found quickly and easily on the Internet. Experience has shown that content published on high-traffic sites is quick and easy to find - university sites and serious research sites are not in this group. Therefore, popular knowledge is quickly and easily discovered on a daily basis, which is very different from the methodically systematized and scientifically tested knowledge, which is the basis of quality higher education;

- Everything is free on the Internet unlike books and textbooks on paper that cost some money. The content published by the various business and non-profit organizations, incl. universities representing their activities, is free. It seems that the popular media content is free, but it is actually not - we pay for it not with our money, but with attention and concentration. Let us not forget that digital access to quality scientific electronic resources or research products in general is paid for limited or unrestricted access no less than access to paper books. This is because authors know the value of their texts and hold and protect the copyright on their intellectual property;

- There are no copyrights on the Internet. This, of course, is not true. Here we come to the issue of copyright regulation and protection of intellectual property in a digital, electronic and online learning environment. This issue is addressed in the Strategy. An Academic Ethics Committee at the Ministry of Education and Science has been established and is committed to resolving copyright cases (2020). It is planed to introduce a "national system for prevention and control of plagiarism in the publication of scientific papers and competitions for academic growth", as well as the use of "modern tools for prevention and control of plagiarism in education and regulation in ethics codes of higher education" (2020). The quality of higher education depends on the quality of intellectual production - monographs, studies and articles, lectures and textbooks, audio-visual content. That is why it is necessary for the Strategy for Development of Higher Education to be conceived through the prism of the European and national regulatory framework and experience in the field of copyright and protection of intellectual property.

In terms of the digital transformation of the learning content, I must also pay attention to „Measure 2.3.4. Focusing on the predominant visualization of the study material. Significant reduction of text-based learning materials at the expense of visual and audio information, which should become the main means of transmitting information to students, and visual and audio information should precede textual“ (2020), provided for in the implementation of "Objective 2. Introduction of modern, flexible and effective forms of education" (2020).

How should we understand this measure? In the process of „universal digitization“ by replacing text with images and sounds?

This is probably because Objective 2 results envisage "visualization of over $50 \%$ of educational material" (2020) by 2030 , i.e. dropping of the text, the word, in other words, approaching the end of the books at the Bulgarian University.

At the same time, it is true that we live in a "civilization of the spectacle", as Mario Vargas Llosa defines our age. It is true that we live in a time of "humiliation of the word“, according to Jacques Ellul's scientific research, however still "in the beginning was the Word," as Christians believe.

If the vision chosen by the Ministry of Education and Science for the development of higher education is defined as an „educational, research and cultural mission for the benefit of society and individuals" (2020); if the Ministry really opposes the use of "the role of higher education as a scientific and spiritual institution" in favour of the ,instrumental role of higher education and its subordination entirely to the needs of the labour market" (2020); if the result towards which the Strategy strives is "a high proportion of graduates with developed abstract, associative and creative thinking, confirmed by their employers" (2020), then instead of a measure that would lead to gradual disappearance of the word and the book from university education, a set of measures should be provided that promote reading and comprehension skills among students and young Bulgarians.

In American universities to this day, freshmen, regardless of their programmes, study disciplines that teach them to create texts and express themselves in writing. This is seen as the basis and essence of the "civic functional literacy" of a young and truly educated generation of professionals. Serious work on and via the Internet is also performed with the help of texts. In this sense, „universal digitalization“ does not mean moving from text to image, from text to presentation, from text to unexplained scheme or from text to an emotionally provocative photo. This distinction is of fundamental importance. The Strategy should combine 
the forms of learning, and not oppose them by sacrificing the work with text and learning to create text.

There are three systems of communication: verbal (text), visual (photos, memes, graphics, diagrams) and auditory (noise, music). Digital literacy and digital competencies require the ability to express not only through the three of them separately, but mostly through balanced combinations of them.

Digitization in relation to the subjects of the learning process - lecturers, means that the lecturer as an "analogue", physical human body and presence is transformed into a "digital" virtual "node" for the dissemination of e-learning content. Their human and social capital does not increase through their transformation from a person into a "node" to justify the claim that digitalisation provides access to quality education. On the contrary, it is possible to provoke demotivation among lecturers in an absolute online environment.

Online education, in order to be of good quality at least to the level of traditional education, requires from teachers and lecturers much more "extracurricular" work and commitment, methodological training and "classroom" for conducting the lectures themselves.

Compensation for the lack of live contact in traditional teaching requires the preparation of appropriate audiovisual materials - animated presentations, individual images, music and videos. It also includes transforming teaching approaches, for example from a mostly monologue to engaging more students into a dialogue, because the opportunity for students to be distracted in the online classrooms is several times greater than in traditional university classrooms. It also requires the use of more expensive and modern technical equipment to access the space of online lectures - relevant hard and software, including antivirus, compatible peripherals such as cameras and microphones, fast and stable Internet, personal space for quiet work.

Lecturers are also required a special psychological attitude towards work in the new technology-mediated teaching environment.

Serious attention is paid to the "high level of age differentiation of Bulgarians in terms of opportunities to work with digital technologies that give great advantages to younger age groups" (2020). We accept this statement with the remark that the different age groups at the university do not have different opportunities, yet different models of working with digital technologies. Compulsory online training during the emerging pandemic crisis of COVID-19 provided ample examples of this in both directions.

The draft of the Strategy introduces a measure for „training lecturers in information processing skills, visual literacy, problem solving and thinking at a higher level, ad hoc cooperation and a deep understanding of how technological tools can improve the learning process" (2020).

If this is a measure that should be implemented from 2021 to 2030, it means that today's lecturers do not have sufficient skills to process information and this is a first-level skill needed to carry out research!

Visual literacy involves, on the one hand, reading and analysing visual information - graphic, diagrams, images, video, and on the other - creating visual information. We all work with it on a daily basis knowledge is transmitted through words and through graphics depicting the words, the meaning, the idea or in other words visual units.

Digitalization in terms of the space in which learning takes place means that the classic living university audience - as a space and environment of the educational process - is transformed into an electronic virtual „room" or "event" in the Internet space.

Because of this transformation the real contact between the lecturer and the students is lost. Since the Athenian philosophical school (V-IV centuries BC) it has been an invariable condition for the teaching and quality education, as well as for continuity between the minds of the epoch. Teaching and accepting knowledge is a process that requires full sensory activity of the participants. Only under the condition that technological "direct" communication is realized, i.e. both parties are at the same time in front of their computer/phone screens and can hear each other.

There are many cases of students combining online lectures and even exams with other activities, such as work, housekeeping, babysitting, parallel surfing the Internet. The combination of learning, working and family, as noted above, has become a basic model of the social situation of today's students. This and other features of "universal digitalization“ mentioned here significantly reduce the effectiveness of the training provided - and this is a problematic situation in terms of the quality of higher education. The goal of providing access to quality education, as set out in the Draft, is often reversed. 
The validity of these three main arguments of the proposal for "universal digitalization" of the educational process by 2030 is also not indisputable. On the contrary - it can be easily refuted. The arguments set out in the Strategy are the following:

- Lack of correspondence between the needs of the digital generation and higher education;

- Technological revolution and general technological transformation, leading to the intensification of the global supply of educational services in higher education;

- The experience of universities in online learning during the COVID-19 crisis.

The first argument has to do with the profile of today's generation of students. The Ministry of Education and Science defines today's students as the "digital generation“ (2020) and notes the lack of compliance of higher education with the needs of the digital generation and with the competencies necessary for successful implementation in the conditions of technological revolution.

What are the specific needs of the digital generation that make them fundamentally different from the needs of previous non-digital generations? What are the means to meet these new specific needs and to achieve a higher level of competence and competitiveness in the labour market of each of today's students?

Our Strategy states that students have "low motivation to receive standard knowledge in the classical way in a lecture hall without the possibility of personalizing the content" (2020). Again, this statement has not been based on serious and representative empirical generational research. It is very strong and generalizing in the Draft and in order to sound convincing enough, it needs a reliable generational profile based on research and sources.

The Draft of the Strategy plans the educational development of three generations - they are named as "Y“, „Z“, „व“, i.e. those born after 1980 until today. Instead of quoting scientific papers that outline relevant generational profiles, it uses information from a website, as many poorly prepared students do in their term papers. Moreover, at the very beginning of the cited publication it was clarified that this generational differentiation reflects Western cultural models, and Japan, Asia and parts of Europe have their own generational profiles based on cultural, political and economic influences (2020a). Under this stipulation, if the proposed generational differentiation is accepted in our country, it has to be specifically justified. Such an approach reveals ignorance of the Ministry of Education and Science of both the research of generations and youth, including Bulgarian, and the generational profile of the object of study in the higher education system.

This approach is unscientific and is not in line with the goal of developing a Strategy for Development of Higher Education. The heart of the quality of higher education is in the research through which we acquire the knowledge we teach. Therefore, the Strategy, in order to be adequate to the object to which it refers, should be built on the basis of an objective research approach, through which to define basic needs and means for their satisfaction, main problems and challenges, generational characteristics and relations, even the peculiarities of public opinion on issues related to higher education. Any other approach is rather an insult to Bulgarian scientists, researchers, and lecturers. Especially applied in this part of the Strategy presenting the views of the authors and their reference groups as public opinion, in this case critical and negative, and the attempt to slip this opinion as „public" to be used as an argument for introduction of the fundamental changes assigned to the Ministry of Education and Science in higher education in our country.

When talking about the values of Bulgarians, it is stated that „education remains a value of paramount importance for Bulgarians" (2020) and only data from a popular survey of public attitudes conducted by a sociological agency in February 2017 is used. This study is out-dated in terms of dynamic social transformations, including the process of digitalization, which intensify each passing year. The results were valid as of February 2017, long before the COVID-19 crisis of early 2020, and if this is the only study and there are no other similar studies conducted, it would be good for the Ministry of Education and Science to assign such a study to Bulgarian scientists. In this way, it will show in practice that it works to "increase the role of science and innovation in the development of a competitive economy and in solving social problems", that it applies "an expert approach in decision-making and in policy formulation and implementation" (2020) and especially considering the drastically changed environment as a result of the pandemic crisis.

Another argument in favour of "universal digitalization" of the learning process is related to the technological revolution and general technological transformation, leading to the intensification of the global supply of educational services in higher education.

The development of the information society as a "global village" with "electronic houses" is an objective 
process that has been going as predicted by futurists Marshall McLuhan in the 1960s and Alvin Toffler in the 1980s. The processes of digitalization of human activity, including the development of effective egovernment, are irreversible. However, there are still human activities whose full electronic or "universal digitalization" is more likely to negatively affect the quality of life. Such are the activities whose effectiveness - economic and sociological, depends on the traditional living contact and intellectual, spiritual and emotional exchange between people.

To be more specific, these are education (secondary and higher) and healthcare. Digital technologies can only partially recreate live communication in its audio-visual perspective. Neither the doctor can hear the patient's heart via the Internet, nor the teacher, the lecturer can feel the vibrations of the brain and the imagination of their students during the lecture.

Under the conditions of the described objective situation, the Ministry of Education and Science detects the danger of "mass entry into the Bulgarian educational space of online and practically oriented courses offered by various platforms and organizations that do not always provide high quality" (2020). Such courses are still offered and have their users. This, of course, will continue, but it should not be perceived as a danger to the development of Bulgarian higher education. Such non-formal education does not compete with higher education - it does not award a state-recognized diploma for a completed educational degree. At best, such non-formal courses, whether online or traditional, can be seen as complementary to formal education and can be an incentive for universities and colleges to develop, like Western European universities, a network of practice-oriented courses for further qualification, retraining or new qualification.

The main challenge facing Bulgarian higher education, to which „universal digitalization“ can be a response, is the high level of competition from higher education institutions in EU Member States that offer easy access, distance learning and free education, and cause an outflow of Bulgarian candidate-students. At the same time there is misunderstanding and unwillingness of Bulgarian universities to develop a higher degree of international competitiveness, as until recently they felt comfortable in the national competitive academic environment (2020).

The digitalization of the educational process or the introduction of online learning would hardly fulfil the role of a competitive advantage of the Bulgarian higher education, which would motivate the Bulgarian candidatestudents to choose to study in Bulgaria. For example, good language and other high schools send their students to continue their education abroad, because this improves their ranking in our country, not caring how many of the successful students come back after the second year with emotional trauma and financial problems. The same is noted in the Draft. This is a process that has been developing for a long time and online university education and "universal digitalization" is not the measure that will stop it.

„Universal digitalization“ alone does not have the potential to reverse the lack of willingness of Bulgarian universities to develop international competitiveness, as envisaged in the Draft. This requires teaching and management competence, ability, and motivation. For this reason, the human factor is leading, not the technological.

Another key argument for the transition to online learning is the successful attempt of universities and colleges to urgently transform traditional learning into online learning, triggered by COVID-19 in the beginning of 2020. „Almost all higher education institutions managed to switch to e-learning in a short time“, states the Draft of the Strategy. The same is defined as "a good basis for the much fuller development of elearning in the future" (2020). The Draft further emphasizes that "the urgent need to digitize all education caused by the outbreak of the COVID-19 pandemic in 2020 only illustrates how urgent and important are changes in higher education and in all other connected spheres of life. What seems to be imposed by an emergency today may turn out to be the mass world standard in the next 2-3 years" (2020).

Objectively speaking, the process of digitalization is irreversible and will continue to develop in the coming years. In this regard, the Draft proposes the introduction of disciplines into the curricula that deal with artificial intelligence ( $\mathrm{Al})$, augmented reality $(\mathrm{AR})$, virtual reality $(\mathrm{VR})$, etc., as well as basic training for skills development needed for algorithmic thinking and solving algorithmic problems (2020). In order to achieve correlation between the training and the needs of the time, this proposal is adequate and quite timely.

Another proposal is related to the creation of Teaching and Research Universities

„Developed system for shared use of facilities and lecturers from higher education institutions“ (2020).

The Strategy, being based on the Higher Education Act, proposes a division of universities into the ones focused on research and teaching and vocational universities. Vocational universities are today's colleges that offer the so-called „professional bachelor's degree“ with duration of study three years. The distinction 
between universities focused on research and the ones on teaching still remains. There is no doubt that this division is artificial and not objectively justified.

The Scientist and the Teacher are one. The scientist, or the researcher, discovers the gifts of the world and their mission is to discover this knowledge, to pass it on to people so that they can benefit from it. But more often people do not want to accept the new things, to change their lives, even if it's for good.

As a result, some scientists despise humans and imprison themselves in their own greatness and loneliness. Separating research universities means helping scientists shut themselves in, isolate themselves and make it harder for them to reach people.

Other scientists decide to sell the knowledge they have gained. These are the Merchant Scientists. For them the idea of a university to be fully focused on teaching is great. Then they can conduct as many lectures as they want and sell what they have read in the works of others.

Finally, the third type is a research scientist. They manage to find a way to reach knowledge and to pass it on and thus to increase the human and social capital of their students. These are the Scientists-Teachers. Not loners. Not merchants who generally have no place in the temple of Science. But Scientists-Teachers. Like Abelard and the prototype of the European university. Abelard discovered the world and gathered people who wanted to learn from him, who wanted him to teach them. This is the university - a unity of Scientists and Lecturers, of research and lectures.

The question is why does the Draft of the Strategy insist on this distinction? Perhaps this is necessary to create an opportunity to restructure the higher education system and to implement the "Objective 10. Improving the structure and efficiency of higher education" (2020).

An important point in the plan for improving the structure is the proposal to close the so-called „uncharacteristic professional fields". Those are fields with "low quality and low level of realization of graduates, „without traditions and capacity“ (2020), which lose the profile of the university.

Logically, the question arises whether these criteria are sufficiently clear and unambiguous for determining a given field, a specialty as an uncharacteristic of any university?

Another proposal is to promote the sharing of facilities from several universities, joint interdisciplinary interuniversity programmes and "shared engagement of lecturers (2020). If several universities in a region share one mathematics lecturer, for example, this raises the question of amending the existing Higher Education Act, according to which one lecturer can participate in the accreditation of only 1 university. Defending the same rule is included in the Strategy as a measure to improve the quality of higher education.

To which university will the shared lecturer be accredited? The same question applies to interuniversity programmes - to which university will they be accredited?

The answer can be found in „Measure 10.1.6. Encouraging the unification of higher education institutions on a voluntary basis and the creation of higher education consortia" (2020), which is actually in line with the World Bank's recommendation of 2012 to merge universities as a basis for higher education reform (2012). The merge can take place from top to bottom - through active action, by order of the relevant authorities or from bottom to top - at the initiative of the universities themselves.

Obviously the preferred approach is the second one. It guarantees lack of conflict around the institution managing the merge. It is carried out through sharing of material and human resources, curricula and ends with university consortia. In this situation, the answer to the question in the accreditation of which university the shared lecturers will participate - is the new university, created after the merge.

However, another question arises. Why the Ministry of Education and Science is planning a voluntary merge of universities, after thoroughly arguing later on in the Draft that the number of universities in Bulgaria per 1 million inhabitants is not excessively high, but is in line with EU countries; that not the number of the universities, yet the revealed uncharacteristic directions and specialties lower the quality of the education?

The improved structure of universities needs to be stratified.

The main criteria for this, obviously, will be the labels "research“ - the highest ranking, „teaching“ - the middle and "vocational“ - the lowest ranking of a university. It is possible that this labelling will affect the process of merging universities - the merge will focus on research university and the restructuring of the university space.

As the proposals for closing uncharacteristic specialties, labelling and merging of universities may disturb the 
universities outside Sofia, the Draft of the Strategy proposes „Goal 8. Increasing the role of higher education as an active factor in regional development" (2020). The goal, activities and measures are essential for the development of the regions and the mission of the regional university and if it is completed and not just recorded in order to neutralize possible tensions, the effects would be quite beneficial not only on higher education but also on development of the Bulgarian society as a system.

\section{CONCLUSION}

For a long time, education was seen as a priority in every programme, but it never became a real priority in government policies. It is high time to stop the partial changes caused by specific situations and desires that lead to the occurrence of more problems than there are solved.

The transition from general and comprehensive to quality education for every Bulgarian citizen, including all dimensions of the modern educational space - formal, non-formal, informal and the creation of an educational environment is a real factor for sustainable economic development. The transformation of education into an intelligent tool for economic development in the following main directions (Bogdanova, Terziev, 2019; Terziev, 2019a; Georgiev, 2019b; Petrov, Georgiev, 2019c):

- Regionalization of secondary education, in line with the priority areas for development; technical and technological orientation, corresponding to the type of the economy; degree of interactivity and digitalization that ensure the operational management of technological and economic processes with sufficient interaction with economic entitie;

- A new model for the development of higher education, providing a basis for the development of science and a basis for accelerated innovative economic development; reconsidering the legal framework for autonomy and accreditation and creating rating systems with a view to balanced management, control over resources and the development of academic potential. Providing opportunities for concentration of resources by creating different types of higher education institutions, colleges, institutes and universities, corresponding to different requirements of social and economic development and overcoming the low level of professional realization.

\section{REFERENCE LIST}

Draft of Strategy for development of higher education in the Republic of Bulgaria for the period 2021-2030 (2020). http://strategy.bg/PublicConsultations/View.aspx?lang=bg-BG\&ld=5238.

https://www.careerplanner.com/Career-Articles/Generations.cfm (2020a).

World Bank. (2012). Strengthening higher education in Bulgaria. Report. 2012

Bogdanova, M., Terziev, V. (2019). Akademicheskiy kapitalizm i novaya biznes modely universitetov. // Mezhdunarodnayy nauchnayy zhurnal, Innovatsionnaya nauka, „Aeterna“, Ufa, 9, 2019, s. 32-39, ISSN 2410-6070 (Богданова, М., Терзиев, В. Академический капитализм и новая бизнес модель университетов. // Международный научный журнал, Инновационная наука, „Аэтерна“, Уфа, 9, 2019, с. 32-39, ISSN 2410-6070).

Terziev, Venelin. (2019a). The development of education in Bulgaria. // Proceedings of SOCIOINT 2019-6th International Conference on Education, Social Sciences and Humanities 24-26 June 2019- Istanbul, Turkey, International Organization Center of Academic Research, Istanbul, Turkey, 2019, pp. 263-266, ISBN: 978-605-82433-6-1.

Georgiev, M. (2019b). Improvement of the forming of the military professional qualities during the educational process. // 21 st International scientific conference: The teacher of the future, Budva, Montenegro, (07-09.06.2019), Institute of knowledge management - Skopje, Macedonia, 31, 2019, 6, pp. 1945-1950, ISSN 1857-923X (for e-version), ISSN 2545 - 4439 (for printed version).

Petrov, N., Georgiev, M. (2019c). Assessing of the military professional competencies. // Proceedings of SOCIOINT 2019- 6th International Conference on Education, Social Scienc-es and Humanities 24-26 June 2019- Istanbul, Turkey, International Organization Center of Academic Research, Istanbul, Turkey, 2019, pp. 462-472, ISBN: 978-605-82433-6-1. 